\title{
FADD regulates thymocyte development at the $\beta$-selection checkpoint by modulating Notch signaling
}

\author{
X Zhang ${ }^{1}$, X Dong ${ }^{1}$, H Wang ${ }^{1}$, J Li ${ }^{1}$, B Yang ${ }^{1}$, J Zhang ${ }^{1}$ and Z-C Hua ${ }^{\star, 1,2}$
}

Non-apoptotic functions of Fas-associated protein with death domain (FADD) have been implicated in T lineage lymphocytes, but the nature of FADD-dependent non-apoptotic mechanism in early T-cell development has not been completely elucidated. In this study, we show that tissue-specific deletion of FADD in immature (CD44- $\left.{ }^{-} D 25^{+}\right)$thymocytes results in severe perturbation of $\alpha \beta$ lineage development. Meanwhile, loss of FADD signaling at a later (CD44-CD25) developmental stage does not affect subsequent T-cell development. Collectively, our work presents that FADD deficiency induces failed survival in double-negative 4 (DN4) cells, while pre-T-cell receptor (TCR) signal remains intact. In addition, Notch signaling is positive regulated on DN4 and double-positive thymocytes in T-cell-specific FADD-knockout mice, which express higher levels of a subset of Notch-target genes, including Hes1, Deltex1 and CD25. Moreover, a transcriptional repressor of Notch1, NKAP is downregulated coupled with the loss of FADD in thymocytes and is found to associate with FADD. These data suggest that as a death receptor, FADD is also required for cell survival in $\beta$-selection as a regulator of Notch1 expression.

Cell Death and Disease (2014) 5, e1273; doi:10.1038/cddis.2014.198; published online 5 June 2014

Subject Category: Immunity

T cells develop in thymus through a series of tightly regulated steps. The thymic immature $\mathrm{CD} 4^{-} \mathrm{CD} 8^{-}$double-negative (DN) $\mathrm{T}$ cells develop into $\mathrm{CD} 4{ }^{+} \mathrm{CD} 8^{+}$double-positive (DP) and then to $\mathrm{CD} 4{ }^{+} \mathrm{CD} 8^{-}$single-positive (SP; CD4SP) or $\mathrm{CD} 4^{-} \mathrm{CD} 8{ }^{+}$(CD8SP) thymocytes. The DN cells can further subdivide into the sequential stages DN1 $\left(\mathrm{CD} 44^{+} \mathrm{CD} 25^{-}\right)$, DN2 $\left(\mathrm{CD} 44^{+} \mathrm{CD}_{25}{ }^{+}\right)$, DN3 $\left(\mathrm{CD} 44^{-} \mathrm{CD} 25^{+}\right)$and DN4 $\left(\mathrm{CD} 44^{-} \mathrm{CD} 25^{-}\right)$. There are several checkpoints in T-cell development. ${ }^{1}$ The first occurs at the DN3 stage and is known as $\beta$-selection. At this point, a properly rearranged T-cell receptor $\beta(\mathrm{TCR} \beta)$ chain pairs with pre-TCR $\alpha(\mathrm{pT} \alpha)$ to form the pre-TCR, which signals in a ligand-independent manner to drive proliferation and differentiation to the DP stage. ${ }^{2}$ Failure to productively rearrange TCR- $\beta$, or to transmit pre-TCR signals leads to developmental arrest at the DN3 stage.

Although pre-TCR signaling is necessary for progression through the $\beta$-selection checkpoint, Notch signals are also required for T-cell development. Notch comprises a family (Notch 1-4 in mammals) of transmembrane receptors. ${ }^{3,4}$ Upon interaction with a ligand (members of the Delta-like and Jagged families), two separate proteolytic cleavage events release the intracellular domain of Notch (ICN), which translocates to the nucleus, then results in chromatin remodeling and expression of Notch-target genes. During T-cell development, expression of Notch-target genes is highly regulated. The expression of Notch-target gene is 'on' at the DN thymic progenitor stage, but is turned 'off' by the DP stage. ${ }^{5-7}$ Conditional deletion of Notch1 using Lck-cre transgenics, or inhibition of Notch signaling using an inducible dominant-negative MAML1, results in arrest of T-cell development at the DN3 to DP transition. ${ }^{8,9}$ Notch also provides important metabolic functions in DN3 cells. ${ }^{10-12}$ However, although Notch signaling is required for $\mathrm{T}$ cell to progress past the DN3/ $\beta$-selection checkpoint, there is one report that high levels of Notch signaling can also block T-cell development. ${ }^{13}$

Fas-associated protein with death domain (FADD) is an adaptor protein critical for the death receptors (DRs) apoptotic signaling. ${ }^{14,15}$ For a long time, FADD was known to interact with Fas, ${ }^{16,17}$ tumor necrosis factor receptor 1 (TNF-R1), DRs and TRAIL receptors, ${ }^{18-21}$ leading to the recruitment of procaspase- 8 and its activation, then consequent apoptosis of the cells. ${ }^{22}$ FADD-deficient mouse embryo fibroblasts (MEFs) or Jurkat T cells are completely resistant to apoptosis mediated by anti-Fas agonist antibody (Ab), TNF- $\alpha$ or TRAIL. ${ }^{20,21,23}$

Although there are in-depth understandings about FADD-mediated apoptotic signaling pathway, relatively little is known about the nature of FADD-dependent non-apoptotic function. One of the major studies on non-apoptotic FADD focused on T lymphocytes using FADD or its mutant transgenic mice. These mice are suggested to fall into three modes: FADD domain-negative mice, ${ }^{14,24} \mathrm{FADD}^{-1-}$ chimeras in a background devoid of immune system $\left(\mathrm{FADD}^{-1-} \rightarrow\right.$ RAG- $\left.1^{-1-}\right)^{23,25}$ and T-cell-specific FADD knockout mice. ${ }^{26-28}$ Based on studies on these mice, a principal conclusion that FADD is required for T-cell proliferation can be drawn.

\footnotetext{
${ }^{1}$ State Key Laboratory of Pharmaceutical Biotechnology, Department of Biochemistry, College of Life Sciences and School of Stomatology, Affiliated Stomatological Hospital, Nanjing University, Nanjing, China and ${ }^{2}$ Changzhou High-Tech Research Institute of Nanjing University and Jiangsu Target-Pharma Laboratories Inc., Changzhou, China ${ }^{*}$ Corresponding author: Z-C Hua, State Key Laboratory of Pharmaceutical Biotechnology, College of Life Sciences and School of Stomatology, Affiliated Stomatological Hospital, Nanjing University, Hankou Road 22, Nanjing 210093, Jiangsu Province, China. Tel/Fax: +86 25 83324605; E-mail: huazc@nju.edu.cn Keywords: FADD; T-cell development; $\beta$-selection; apoptosis; Notch

Abbreviations: DN, double negative; DP, double positive; SP, single positive; TCR, T-cell receptor; FADD, Fas-associated protein with death domain; NICD1, intracellular domain of Notch1; Abs, antibodies; MEFs, mouse embryo fibroblasts

Received 05.12.13; revised 01.4.14; accepted 02.4.14; Edited by A Stephanou
} 
However, the results gained was controversial among these models, just as FADD deficiency induced a severe thymic development arrest in Lck-cre FADD mice ${ }^{26}$ but not in CD4cre FADD mice ${ }^{28}$ or Lck-cre/CD4-cre FADD-EGFP mice. ${ }^{27}$ Moreover, the detailed mechanism of how FADD regulates T-cell development still remained unraveled.

To address these questions and also to investigate the essential roles of FADD in $T$ lineage, we produce two Cre/loxP-mediated T-cell-specific FADD knockout mice: CD4-Cre-dependent T-cell-specific FADD knockout mice (CD4-FADD) and Lck-Cre-dependent T-cell-specific FADD knockout mice (Lck-FADD). It is crucial to generate both CD4-FADD mice and Lck-FADD mice simultaneously and comparatively, although the latter has been produced and reported in another study. In this study, we show that deletion of FADD induce increasing apoptosis coupled with activated Notch1 signaling in DN4 thymocytes of Lck-FADD mice. In conclusion, we conclude that FADD deficiency leads to inhibition of T-cell development at the $\mathrm{CD} 4^{-} \mathrm{CD} 8^{-}$stage and may be a result of Notch1 signaling activation.

\section{Results}

$\alpha \beta$ Lineage development is partially blocked at the early DN3 stage only in intrathymic deletion of FADD by Lck-Cre but not CD4-Cre transgene. The floxed FADD mice were bred to Lck-cre/CD4-cre transgenic mice, which initiate deletion as early as the DN2 or DN4 stage of T-cell development. With an efficient T-cell-specific deletion of FADD (Supplementary Figure S1), Lck-FADD mice had a significant reduction in thymus size and thymic cellularity, while there was no significant difference in the thymic cellularity of CD4-FADD mice (Figures 1a and b). Lck-FADD thymocytes showed an increase in the percentage of DN and a decrease in DP T cells as compared with their littermate controls. In terms of absolute cell numbers, this translated a

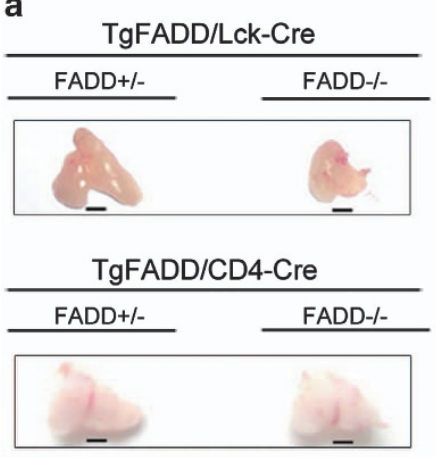

b

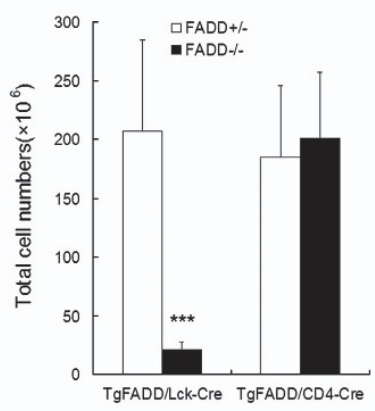

C
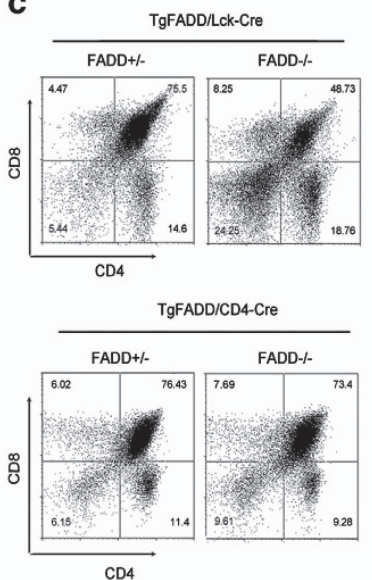

CD4

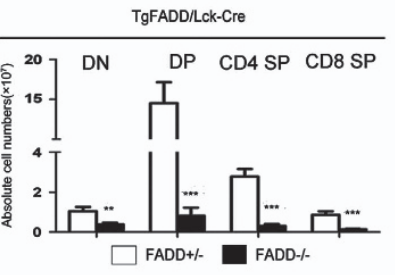

TgFADD/CD4CCre

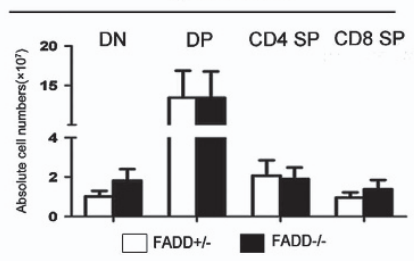

d
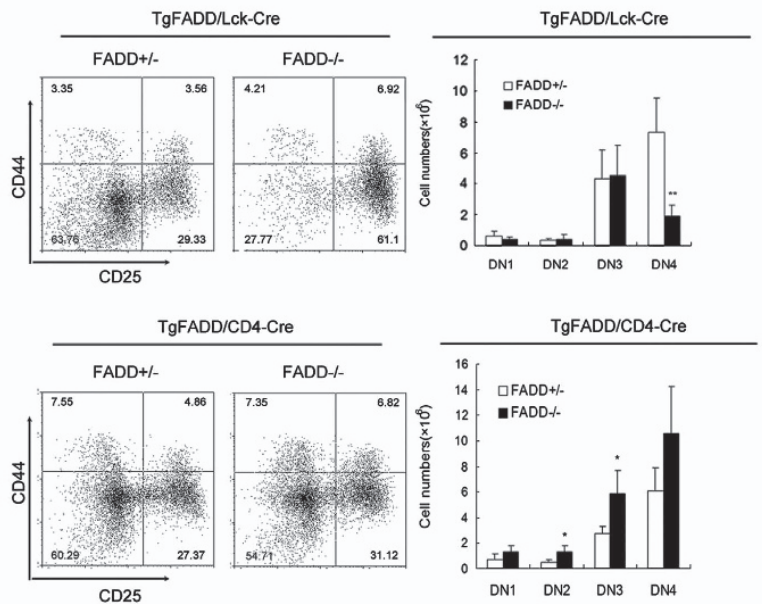

gFADD/CD4-Cre

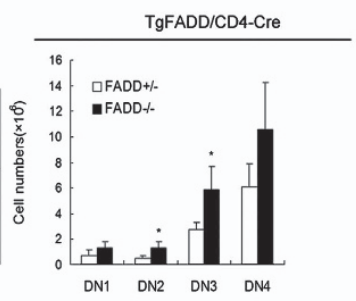

e
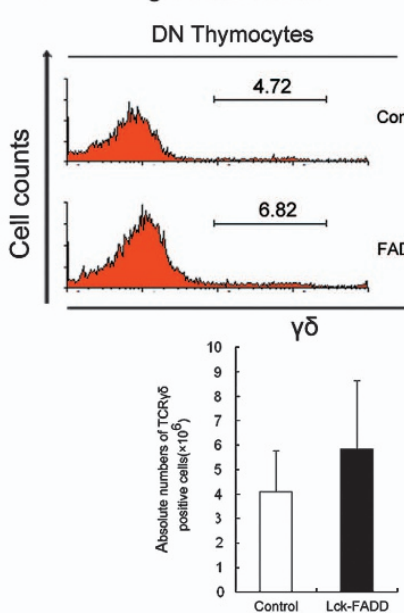

TgFADD/CD4-Cre DN Thymocytes
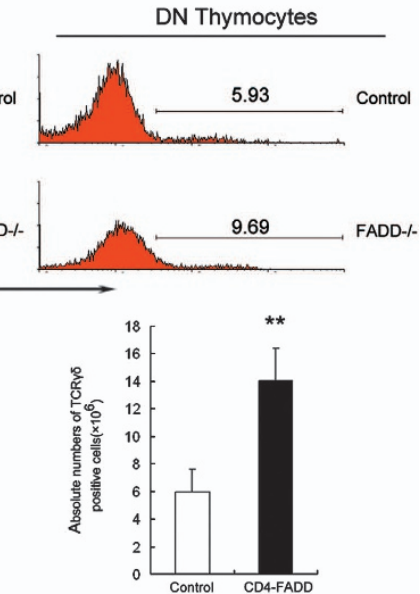

Figure 1 FADD deficiency impairs early thymocyte development only in Lck-FADD mice. (a) Thymus from a Lck-FADD mice (up, 7 weeks) and CD4-FADD mice (low, 5 weeks) with their littermate controls. Horizontal bar stands for $2 \mathrm{~mm}$. (b) Thymic cellularity of Lck-FADD and CD4-FADD mice. Histograms depict the thymus total cellularity. S.D. calculated from five mice. ${ }^{* \star *} P<0.001$. (c and e) Representative flow cytometric analysis of thymus of Lck-FADD (up) and CD4-FADD mice (low) and their littermate control. Thymocytes were stained by using Abs to $\operatorname{CD} 4$ and $\operatorname{CD} 8$ or $\operatorname{TCR} \gamma \delta(n>3)$. The percentage for each quadrant is displayed in the appropriate quadrant. Each plot represents at least 10000 events. Histograms showing absolute numbers of thymic populations in the different Tg mice or littermate controls. ${ }^{* *} P<0.01$. (d) DN thymocytes stained with anti-CD44 and anti-CD25 to identify DN1-DN4 thymocytes from Lck-FADD (up) and CD4-FADD mice (low) with their littermate control ( $n>3$ ). Absolute numbers of total DN3 and DN4 cells from five Tg mice and four littermate controls were calculated, as in Figure 1c above 
into fewer DP, CD4 SP and CD8 SP thymocytes in Lck-FADD mice, which was observed neither in CD4-FADD nor WT mice (Figure 1c). Meanwhile, an obvious decrease of DN cells in terms of absolute cell numbers was observed, suggesting that the loss of thymocytes in Lck-FADD mice may be due to a block of differentiation between DN and DP cells. With further analysis of DN thymocytes, there was an accumulation of DN3 thymocytes and a corresponding decrease of DN4 T cells in Lck-FADD mice but not CD4FADD mice. Although there was no significant effect of FADD deletion on the numbers of DN1-3 thymic subsets, Lck-FADD mice consistently showed a reduction in the number of DN4 cells and an increase in the DN3:DN4 ratio (Figure 1d). This decrease in the number of DN4 thymocytes accounted for much of the decrease in total DN cells, indicating that the block initiated as cells transited from DN3 to DN4 stage. Unlike the Lck-FADD mice, the absolute number of DN2 and DN3 cells in CD4-FADD mice increased as a result of the accumulation of DN cells, although there was lack of a significant difference between FADD $^{-1-}$ and control DN thymocytes (Figure 1d). Furthermore, no defect in production of ISP cells and the positive selection was observed in Lck-FADD mice (Supplementary Figure S2). Therefore, the absence of FADD may have a greater importance in the DN stage than DP stage. Although $\alpha \beta$ T-cell development was disrupted, quantification of the thymocyte population demonstrates that there was no reduction in the absolute number of $\gamma \delta$ T cells, suggesting that $\gamma \delta$ T-cell development was not arrested in the thymus from Lck-FADD mice (Figure 1e).

The block at the DN3 to DP transition is not due to loss of pre-TCR signaling. Considering that thymocyte development was arrested only in Lck-FADD mice, coupled with a reduction in percent and absolute number of DN4 cells, we investigated whether deletion of FADD could interfere with the critical pre-TCR checkpoint. DN3 cells can be separated into pre-selection DN3a and post-selection DN3b cells based upon forward scatter and upregulation of CD27 under the control of pre-TCR signaling. Only a mild decrease was observed in the proportion of post-selection DN3b cells of Lck-FADD mice (Figure 2a). Meanwhile, although the percentage of $\operatorname{TCR} \beta$-positive DN4 cells was obviously reduced, similar levels of TCR $\beta$ was expressed in DN3 cells from WT or Lck-FADD mice (Figure 2b). Furthermore, Lck-FADD DN4 cells have a similar or greater proportion of cells expressing CD5 and CD69 (Figures 2c and $d$ ). Therefore, the block at the DN3 to DN4 transition upon loss of FADD is not due to abrogation of pre-TCR signaling, but rather may involve the interpretation of the pre-TCR signals.

FADD is required for pre-TCR-mediated survival and proliferation of DN4 thymocytes to bypass the $\boldsymbol{\beta}$-selection checkpoint. The decreased number of DN4 thymocytes seen in the absence of FADD suggested that FADD may be required for either pre-TCR-driven cellular survival or expansion. TUNEL staining of thymus showed increased apoptosis in Lck-FADD mice (Figure 3a). FADD deletion led to an obvious increase in apoptosis in DN4 cells in Lck-FADD mice (Figure 3b), indicating that the developmental block seen upon FADD deletion was due to defective pre-TCR-mediated survival signals to some degree. Compared with Lck-FADD mice, there is no obvious increase in apoptosis of thymocytes at the DN3 or DN4 stage in CD4-FADD mice (Supplementary Figure S3), suggesting that the increased apoptosis in thymocytes in Lck-FADD mice may result from FADD deficiency during $\beta$-selection. However, in both mice, DP cells showed a higher percentage of apoptosis compared with WT controls (Figure $3 \mathrm{~b}$ and Supplementary Figure S3). As the development of thymocytes in CD4-FADD mice remains intact, the increased apoptosis in DP cells may not lead to the severe arrest in Lck-mice, suggesting the defective survival signals in $\beta$-selection is a main reason for the decrease of DN4 cells. There was an obvious increase in activated caspase-3 after FADD deletion in thymocytes (Figure $3 \mathrm{c}$ ). The ratio of necrosis in DN4 cells was small, although there was an increase in thymocytes from Lck-FADD mice (Supplementary Figure S4), showing that the increase in cell death of Lck-FADD DN4 cells may be due to apoptosis other than necrosis. Furthermore, to gain insight into the mechanism of apoptosis after the withdrawal of FADD signals, we examined Lck-FADD thymus for features of apoptotic cells, including caspase activation and loss of mitochondrial membrane potential $(\Delta \Psi \mathrm{m})$. FADD deficiency caused a decrease of pro-caspase- 9 , suggesting caspase- 9 may be cleaved. However, there was only minimal proteolytic processing of procaspase-8 (Figure 3d). Meanwhile, a greater proportion of DN4 cells showed a loss in $(\Delta \Psi \mathrm{m})$ in Lck-cre cko mice (Figure 3e). Thus, the coordinate decrease in $(\Delta \Psi \mathrm{m})$ and increase in caspase-9 activation after FADD withdrawal in pre-T cells is consistent with the induction of the cell-intrinsic mitochondrial pathway of apoptosis.

Meanwhile, the EdU incorporation, which is designed to assess pre-TCR-mediated proliferation following $\beta$-selection, was equivalent in DN3 and DN4 thymocytes of Lck-FADD mice compared with WT controls (Figure 3f), indicating that developmental block seen upon FADD deletion may be not due to defective proliferation in DN4 cells.

Loss of FADD leads to increases in Notch-target gene expression. In addition to pre-TCR signaling, Notch signaling also has important roles in thymocyte development. Notch1 signals are required at the DN3 stage as T cells do not survive when Notch signals are withdrawn before $\beta$-selection. ${ }^{29}$ CD25, one of Notch1-target genes, expresses abnormally on the surface of DP and SP cells (Figure 4a, Supplementary Figure S5A). Notch1 expression highly increased at both transcriptional and translational level in total thymocytes of Lck-FADD mice (Figure 4b). Increases in Notch1 and its target gene expression were also observed in the DN4 or DP populations as well (Figures $4 \mathrm{c}$ and $\mathrm{d}$ ). The lack of effect on DN3 for Hes1 and CD25 is likely due to the combination of maximal expression of these genes at this stage of T-cell development.

In order to explore whether the Notch1 signaling pathway was overactivated when FADD was deleted, we overexpressed FADD in WT and FADD ${ }^{-1-}$ MEFs and measured Notch1 expression. The western blotting result showed 

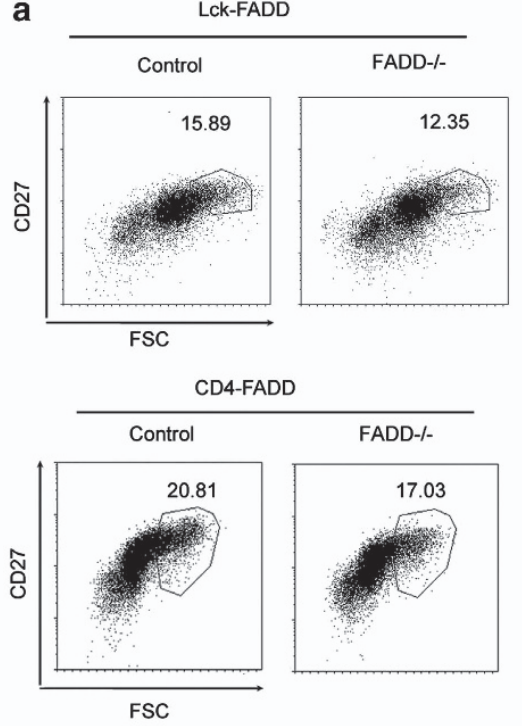

C
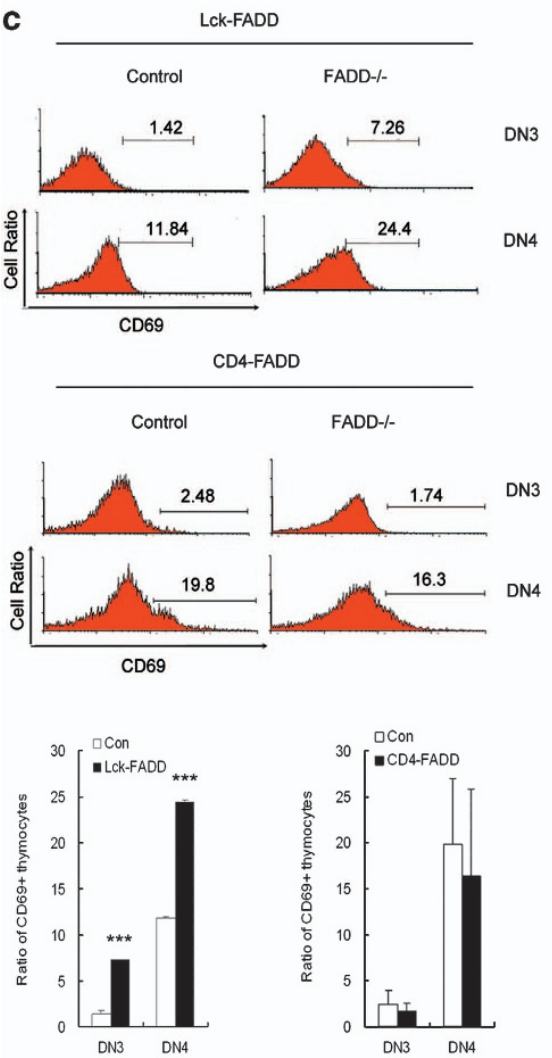

b
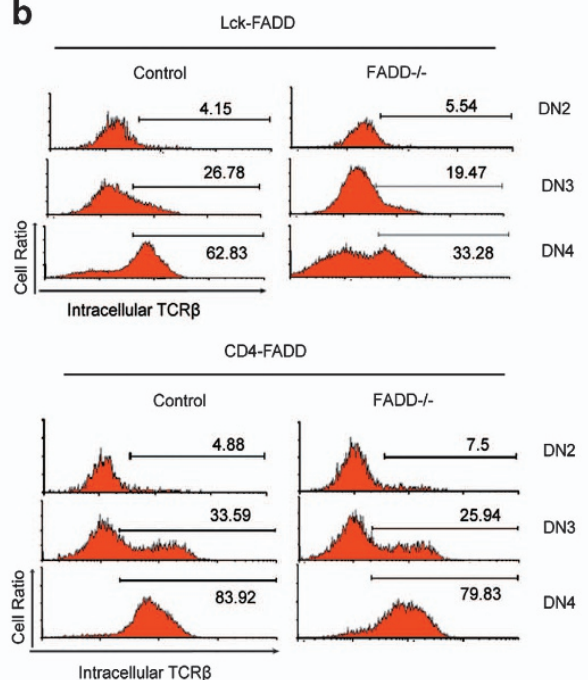

d

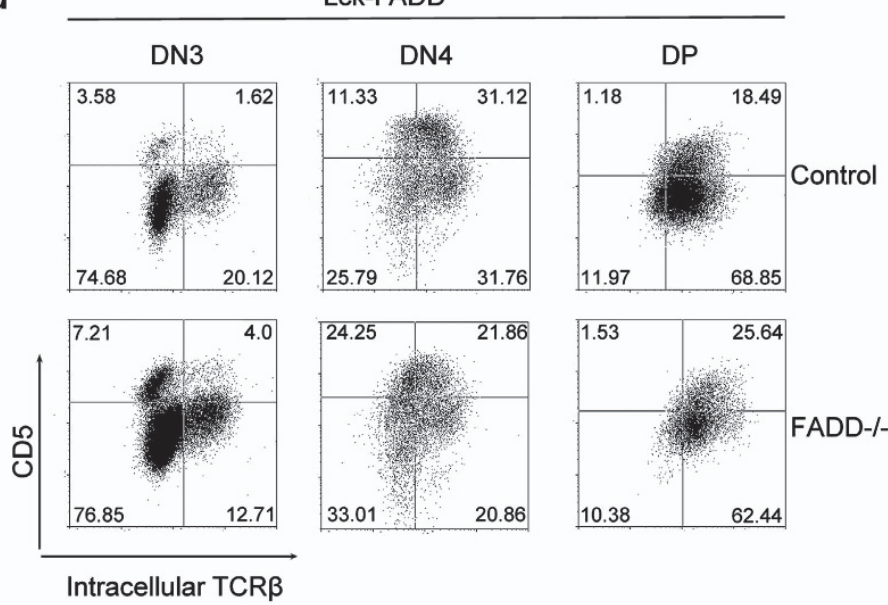

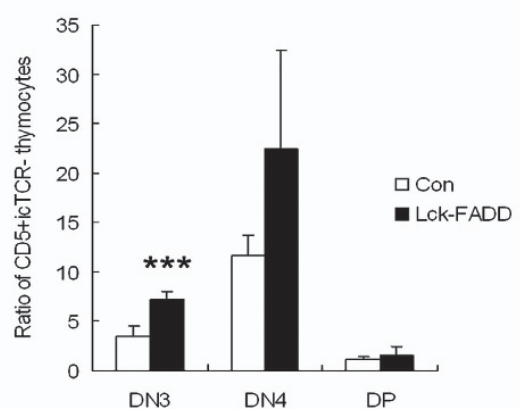

Figure 2 Pre-TCR signaling is intact in Lck-FADD mice. (a) Flow cytometry was performed to analyze the percentage of cells in DN3a (lin ${ }^{-} \mathrm{CD}^{-} 5^{+} \mathrm{c}^{-k i t}{ }^{-}$ $\mathrm{CD} 27^{\text {med }} \mathrm{FSC}^{\text {med }}$ ) and DN3b populations (lin ${ }^{-} \mathrm{CD} 25^{+} \mathrm{c}-\mathrm{kit}^{-} \mathrm{CD} 27^{\mathrm{hi}} \mathrm{FSC} \mathrm{C}^{\mathrm{hi}}$. Shown is a representative FACS plot to show gating strategy, with average DN3b percentage calculated from four Tg mice and three littermate controls also shown. Error bars reflect S.E.M. (b) Flow cytometry was performed to analyze expression of intracellular TCR $\beta$ (ic TCR $\beta$ ) of DN2, DN3 and DN4 cells from Lck-FADD (up) or CD4-FADD (low) mice. Shown are representative data from four independent experiments. ${ }^{* \star *} P<0.001$. (c) FACS was performed to analyze expression of CD69 expression on the cell surface of DN3 and DN4 cells. Shown are representative data from three independent experiments. Error bars reflect S.E.M. ${ }^{* \star} P<0.001$. (d) DN3, DN4 and DP thymocytes were gated as described in Figure 1. Cell surface CD5 expression and ic TCR $\beta$ expression were analyzed on all subsets. Shown are representative data from three independent experiments. ${ }^{* \star *} P<0.001$

obvious decrease in Notch1 protein levels in both MEFs when exogenous FADD was added, indicating that the increases in Notch-target gene expression may be due to Notch1 activation induced by FADD deficiency (Figure 4e).
The increase of NOTCH expression may be correlated with NKAP, a component of the Notch corepressor complex. Multiple Notch-target genes are co-regulated by E2A and Notch. Pre-TCR signaling increases the expression 
a

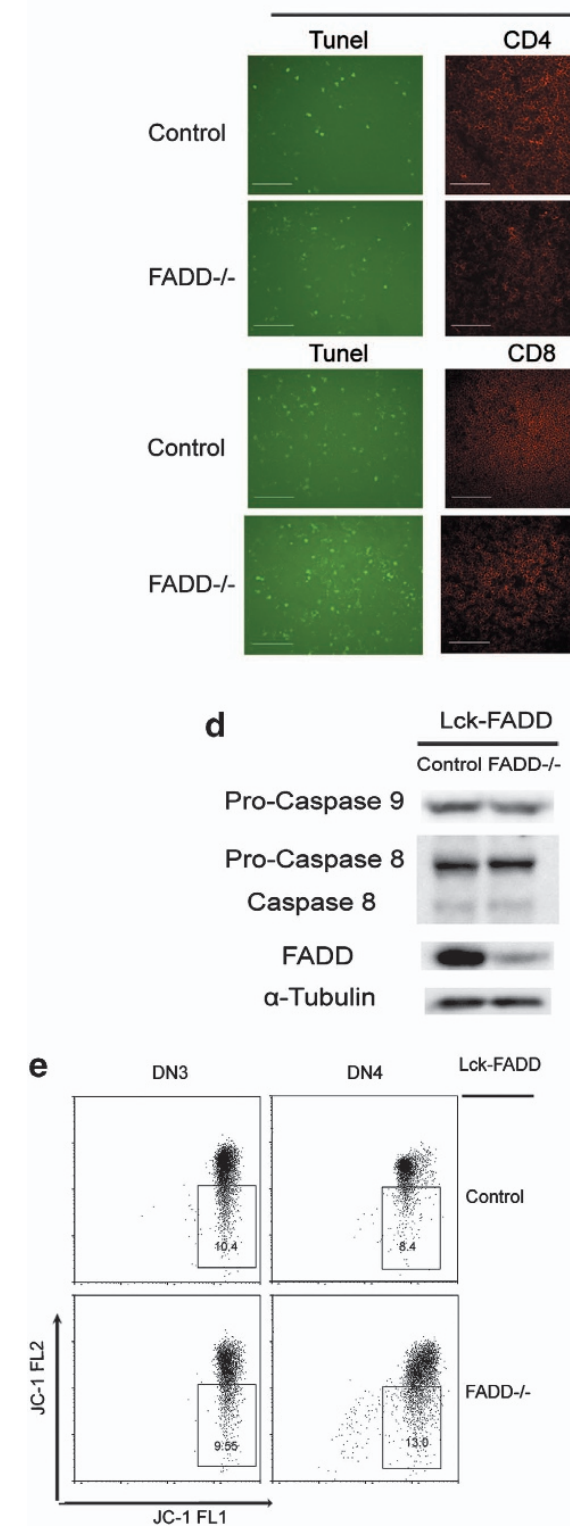

Lck-FADD b

L LCk-FADD

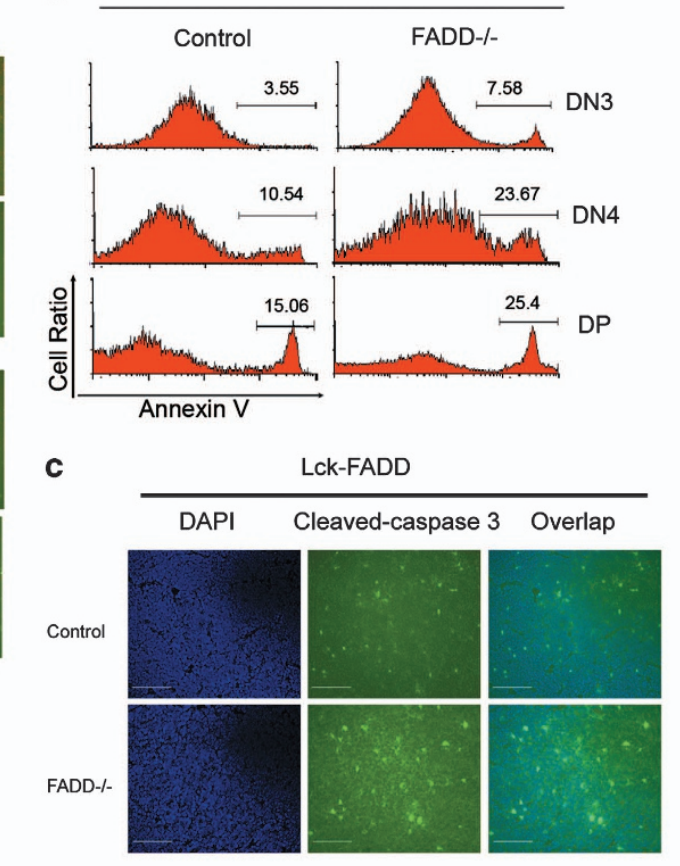

c

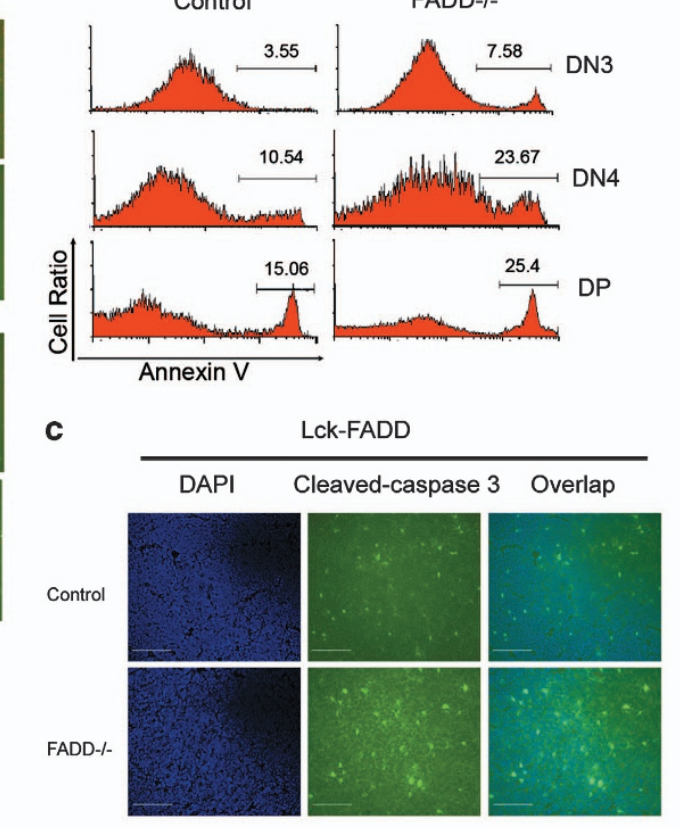

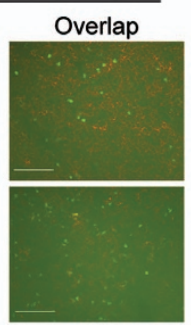

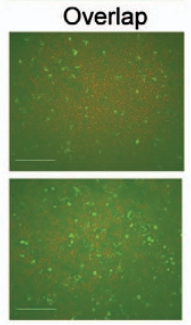

$-1 \cdot \sin$

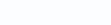


a
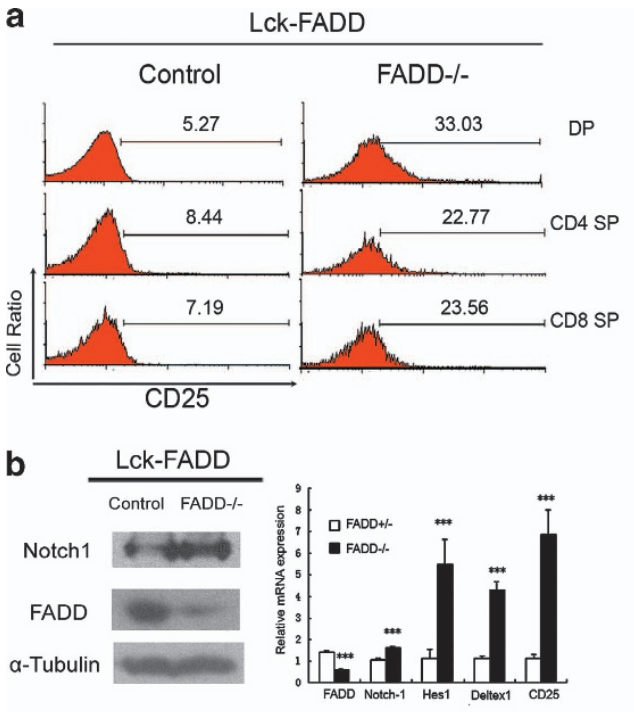

d
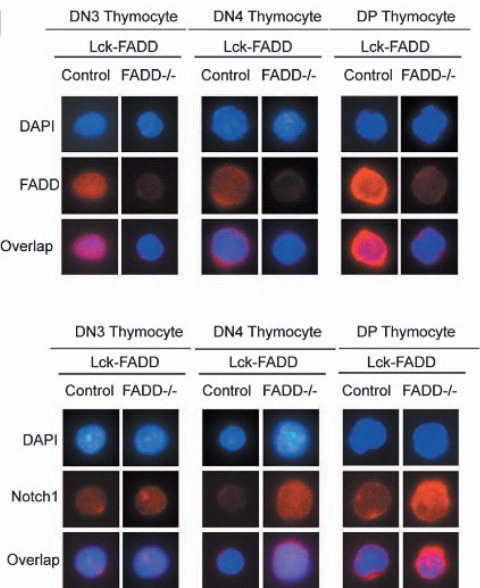

C
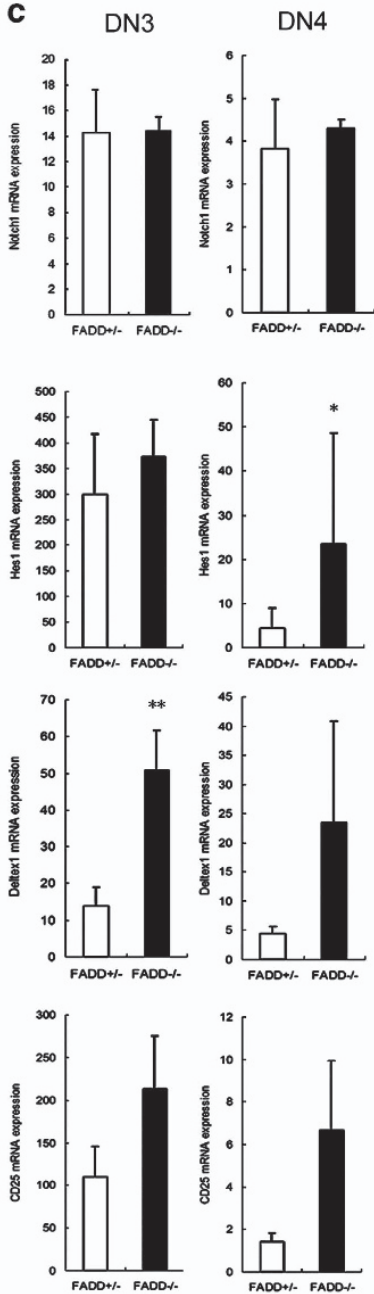

DP

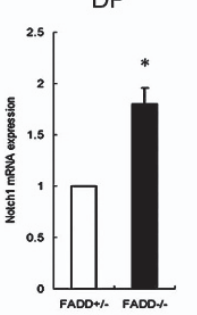

e

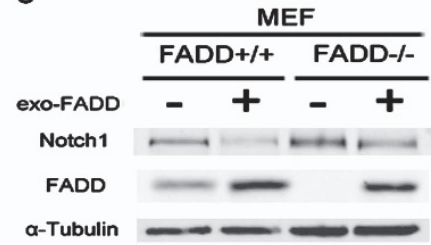

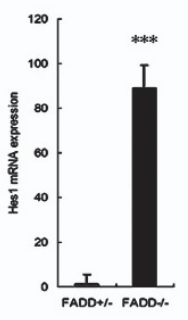
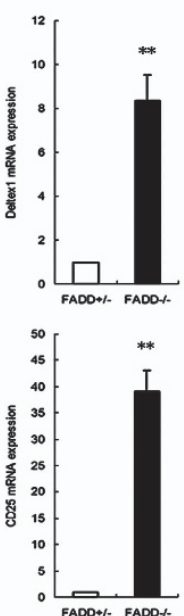

Figure 4 Potentiation of Notch-target gene expression in the absence of FADD. (a) FACS was performed to analyze expression of CD25 expression on the cell surface of DP, CD4 SP and CD8 SP cells. Shown are representative data from three independent experiments. (b) Notch1 western blot (left, $\alpha$-tubulin expression served as a loading control (bottom panel)) and quantitative PCR for Notch1 and its target genes expression of thymocytes from Lck-FADD mice with littermate control (right, $n>3,{ }^{* \star *} P<0.001$ ). (c) DN3, DN4 and DP thymocytes from Lck-FADD mice and littermate control were isolated by FACS sorting. mRNA was generated and examined by quantitative PCR for Notch1, CD25, Hes1 and Deltex1 mRNA expression levels, and normalized relative to the sorted wild-type population with the lowest expression of each gene (=1). The data shown are from three Lck-FADD mice and littermate control, each from independent sorts and independent Q-PCR. Error bars reflect S.E.M. (d) DN3, DN4 and DP thymocytes from Lck-FADD mice and littermate control were isolated by FACS sorting and stained for FADD and DAPI for immunofluorescence analysis of FADD and Notch1 expression. Pictures were taken on a microscope at $\times 1200$ magnification. (e) Immunoblot analysis of Notch1 in WT and FADD ${ }^{-1-}$ MEFs after exogenous FADD was introduced for $24 \mathrm{~h}$. The data shown are from three independent experiments

while DP T cells express 8- to 20-fold higher levels of Hes1, Deltex1 and CD25, ${ }^{30}$ which was similar with the phenotype in Lck-FADD mice. Therefore, we investigated the expression of NKAP in thymus of Lck-FADD mice. The result suggested that there was a sharp decrease in thymocytes from Lck-FADD mice compared with the WT mice (Figure 5f). Moreover, NKAP expression was downregulated at translational level in FADD $^{-/-}$MEFs or Jurkat cells (Figure $5 \mathrm{~g}$ ). In order to find the relation between the expression of NKAP and Notch1, MEFs were transfected with a NKAP-specific siRNA and the effects of gene silence were measured using Q-PCR and western blotting. It was observed that the siRNA markedly decreased the NKAP expression at the level of both transcription and translation. Meanwhile, the level of Notch1 was elevated as NKAP gene was silenced, indicating that the Notch1 accumulation may result from loss of NKAP (Figure $5 \mathrm{~h}$ ).
NKAP associates with FADD. As it was indicated that NKAP interacts with RIP in yeast, we speculated that there may be an interaction between FADD and NKAP. To confirm this hypothesis, 293T cells were transfected with FLAGtagged FADD, HA-tagged NKAP or vector controls. FADD was found co-immunoprecipitated with NKAP (Figure 6a). In its initial description, NKAP was found to localize to nuclei in a punctate pattern, ${ }^{30}$ while FADD was observed to exhibit concentration in the nucleus of a series of cell lines. ${ }^{31} \mathrm{HA}-$ NKAP and FLAG-tagged FADD colocalized in a punctate nuclear pattern in 293T cells, while HA is predominantly cytoplasmic and did not localize with FADD (Figure 6b).

With the investigation that FADD deficiency did not lead to a decreased transcription of NKAP (data not shown), we tried to find out whether the association with FADD may contribute to the stabilization of NKAP. FADD ${ }^{-1-}$ MEFs were transfected 
a

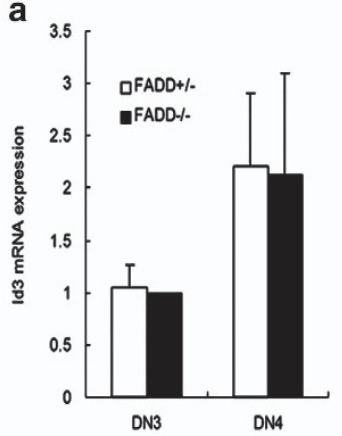

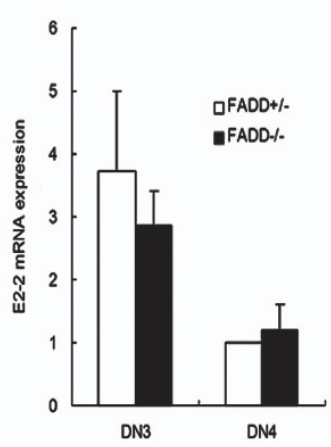

Lck-FADD

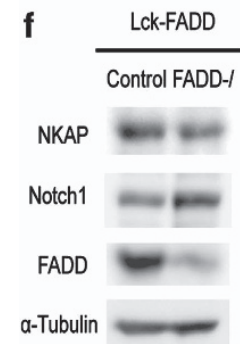

FADD-1-

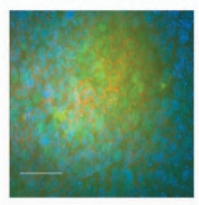

b

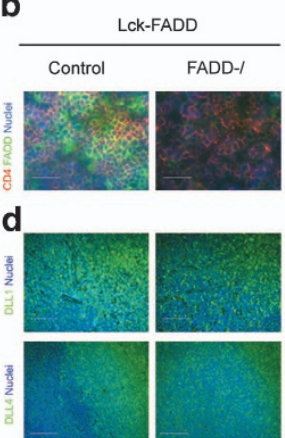

g

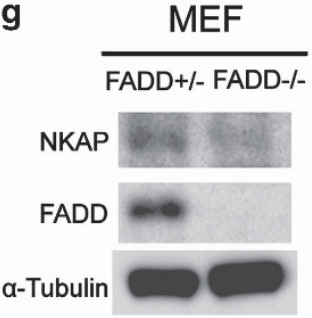

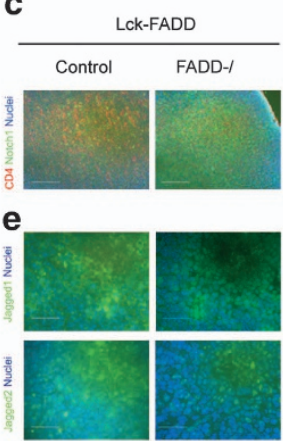

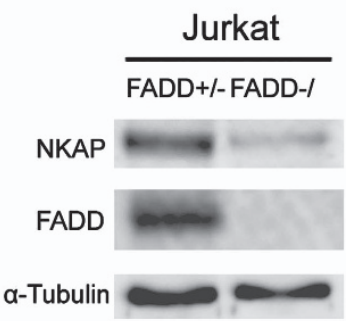

h

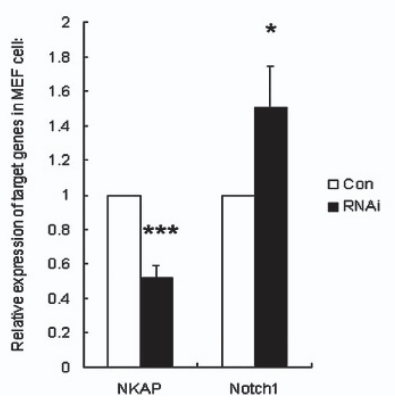

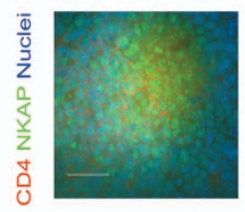

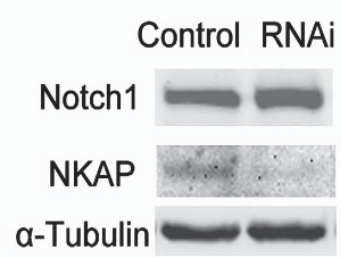

Figure 5 The increase of NOTCH expression coupled with decrease of NKAP. (a) DN3 and DN4 thymocytes from three wild-type and Lck-FADD mice were isolated by FACS sorting. mRNA was generated and examined by quantitative PCR for E2-2 and Id3 mRNA expression levels, and normalized relative to the sorted wild-type population with the lowest expression of each gene $(=1)$. (b-e) Cryosections of thymi were stained with Abs and analyzed by immunofluorescence microscopy to detect the expression of FADD, Notch1 and Notch ligands in the thymus of Lck-FADD mice and littermate control. Scale bars: (b and e) $20 \mu \mathrm{m}$; (d) $50 \mu \mathrm{m}$; (c) $100 \mu \mathrm{m}$. (f) NKAP western blots and immunofluorescence analyze were performed on the thymus of Lck-FADD mice and littermate control. Scale bar: $20 \mu \mathrm{m}$. (g) NKAP western blots were performed on WT and FADD $^{-1-}$ MEFs or Jurkat cells. Data are representative of three independent experiments. (h) MEF cells were transfected with a NKAP-specific siRNA and the expression of NKAP and Notch1 were measured using Q-PCR and western blotting. The data shown are from three independent experiments. ${ }^{\star} P<0.05$, ${ }^{\star \star \star} P<0.001$

with FADD and NKAP, we found obvious increase in NKAP protein levels when exogenous NKAP was added (Figure 6c). Further, co-expression of NKAP with FADD produced a corresponding increase in the amount of NKAP when FADD protein levels were elevated (Figure 6c). Meanwhile, cotransfection of FADD with NKAP resulted in the marked recruitment of the FADD to the nuclear and colocalization with NKAP (Figure 6d). These observations suggested a potential role of FADD in maintaining the stabilization of NKAP by association and colocalization.

\section{Discussion}

This study provides genetic evidence for that despite being a death adaptor molecular, FADD is also required for T-cell proliferation and cell cycle progression. It was reported that the lack of proliferation of $\mathrm{FADD}^{-1-} \mathrm{T}$ lymphocytes results from defective survival rather than defective activation and cell cycle progression. ${ }^{32}$ However, according to recent studies, there still remained paradoxical results about the roles of FADD in early T-cell development.

Several mouse lines that direct Cre expression to lymphoid progenitors in the thymus have been established, in which FADD gene was inactivated during different stages of T-cell development. One of the most used models is CD4-cre transgenic mouse, in which the Cre recombinase is not expressed until after the DN3 checkpoint. ${ }^{33}$ Between the DN and DP stages, thymocytes would begin to express the transgenic Cre recombinase, which would result in deletion of the target gene and a population of thymocytes that was deficient in target protein. ${ }^{34}$ Unlike the CD4 promoter, the Lck proximal promoter becomes most effective in thymocytes starting from the DN3 stage. ${ }^{35,36}$ When Lck-cre transgene is introduced, the effective deletion of target gene starts from the DN3 stage and the obvious deletion is often observed from the DN4 stage and onward. ${ }^{37}$ Therefore, compared with Lck-cre transgene, the CD4-cre system would allow for an appropriate pre-TCR signal with progression to the DP stage and 
a

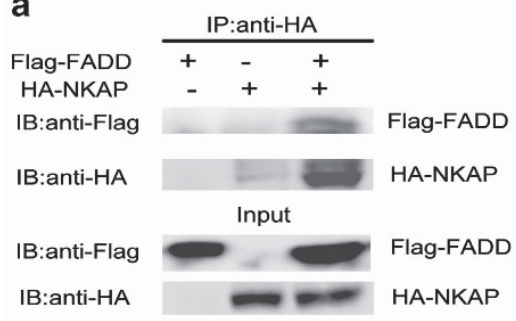

C

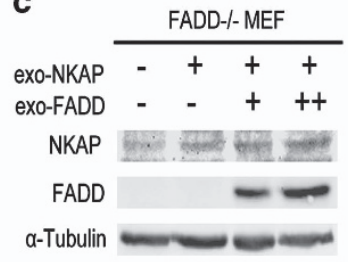

b

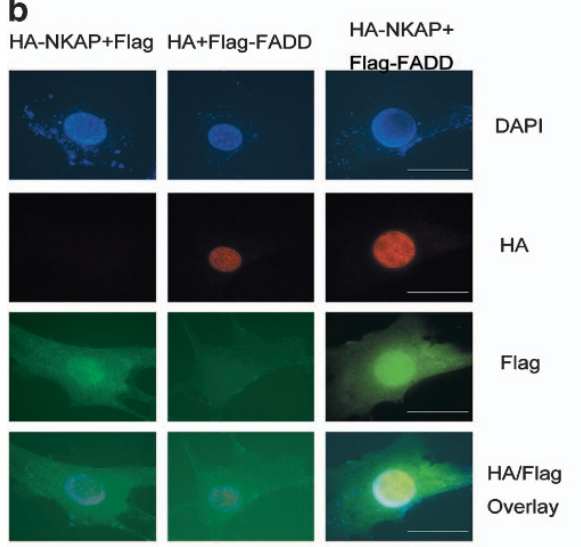

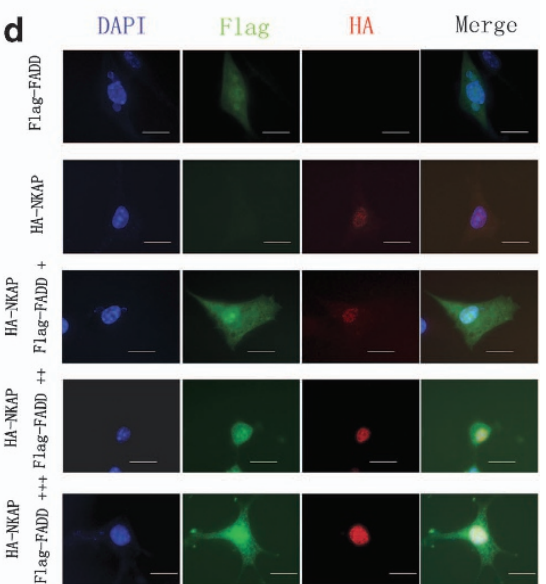

Figure 6 Association and colocalization of NKAP with FADD. (a) 293T cells were transfected with HA or HA-NKAP expression plasmids, with either empty vector or FLAGFADD. The next day, cell extracts were generated and subject to immunoprecipitation with anti-HA. Samples of extracts (WCE) and immunoprecipitates (IP) were analyzed by western blots with either anti-FLAG to examine FADD co-precipitation or anti-HA to assess immunoprecipitation. (b) NIH3T3 cells were transfected with either HA or HANKAP, in addition to FLAG-FADD expression plasmids. The next day, cells were fixed, permeabilized and stained with rabbit anti-FLAG and mouse anti-HA. DAPI was used to delineate nuclei. In the bottom panel, FLAG and HA are overlaid. Scale bar: $20 \mu \mathrm{m}$. (c) Western blot analysis of protein expression in FADD ${ }^{-I-} \mathrm{MEFs}$, while exogenous NKAP were expressed alone or co-expressed with FADD. Data are representative of three independent experiments. (d) Effect of co-expression with FADD on NKAP expression was studied by immunofluorescence microscopy. FADD ${ }^{-1}-$ MEFs were transiently transfected with HA-NKAP expression plasmids in the absence or presence of FLAG-FADD. At $48 \mathrm{~h}$ after transfection, cells were fixed and subjected to immunostaining for analyses. Scale bar: $10 \mu \mathrm{m}$

potentially beyond. As FADD deficiency induced a severe thymic development arrest in Lck-cre FADD mice but not in CD4-cre FADD mice, we think it takes a great importance to produce and to analyze the two types of $\mathrm{FADD}^{-/-}$mice comparatively.

In this article, we generated and compared two Cre/loxPmediated T-cell-specific FADD knockout mice in which FADD was deleted in different stages of thymocytes. Our observation that FADD deficiency caused a reduction in overall thymocyte numbers and a partial block at the DN-to-DP transition only in Lck-FADD mice demonstrates that FADD has a crucial role in $\beta$-selection, an important checkpoint occurring from the DN3 to DN4 stage of thymocyte development. Although the percentage of DN3b cells and the expression of TCR $\beta$, CD25 and CD69 in DN3 cells were not changed in Lck-FADD mice, it showed that the pre-TCR signal may remain intact and the development arrest is likely due to other factors. When focusing on the mechanism inducing the decrease of DN4 cells, a severe apoptosis was observed at the DN4 stage, which may account for the violent cellular decrease (and cannot be rescued by introduction of TCR $\beta^{26}$ ). Although the exact signaling pathway leading to FADDdependent T-cell proliferation is presently unclear, it was shown recently that the lack of proliferation of $\mathrm{FADD}^{-1-}$ $T$ lymphocytes results from defective survival rather than defective activation and cell cycle progression. $\mathrm{T}$ cells expressing a dominant-negative form of FADD were shown to enter the cell cycle upon mitogenic stimulation, followed by an arrest of survival associated with progression through the cell cycle. ${ }^{32}$ Inhibition of necroptosis using an inhibitor of RIP1 kinase activity rescues the FADD knockout proliferative defect in peripheral T cells of CD4-FADD mice. ${ }^{28}$

Several independent lines of evidence indicate that the thymic phenotypes observed in Lck-FADD mice depend upon Notch1 signaling in $\beta$-selection. First, expression of Notch1 target genes was highly elevated in DN4 and DP cells in LckFADD mice, indicating that Notch signaling was abnormally activated. In addition, little phenotype was observed in CD4FADD thymus. Under the control of CD4 promoter, FADD deletion in thymocytes finished until DP stage and bypassed the $\beta$-selection checkpoint. This observation reveals that though Notch1 expression also increased in DN4 and DP cells in CD4-FADD mice, it did not affect the thymic development after $\beta$-selection. Notch1 mRNA increases from early thymocyte progenitor to the DN3a stage and markedly decreases at the DN3b stage commensurate with pre-TCR signaling, then remains low throughout the rest of thymocyte development. ${ }^{38}$ Although Notch signaling is required for $T$ cell to progress past the DN3/ $\beta$-selection checkpoint, there is one report that high levels of Notch signaling can also block T-cell development. Rag2-deficient DN3 cells transduced with an ICN1-expressing retrovirus that co-expresses GFP from an internal IRES 
site develop into DP T cells, but only when low/medium levels of GFP/ICN1 are expressed. In contrast, thymocytes expressing high levels of GFP/ICN1 are developmentally arrested and do not develop into DP thymocytes, ${ }^{13}$ indicating that activation of Notch signaling could be partially responsible for the defect in Lck-FADD mice. Similarly, loss of Notch1 degradator Fbxw7 in MEF induced cell cycle arrest and apoptosis that were accompanied by abnormal accumulation of the intracellular domain of Notch1 (NICD1). ${ }^{39}$ Furthermore, blocking of thymic differentiation has been previously shown upon deletion of NKAP, a Notch1 transcriptional repressor from DN3 stage. ${ }^{30}$ It was stated that NKAP deficiency leads to increases in Notch-target gene expression and blocks $\alpha \beta$ T-cell development at the DN3 stage, which was also observed in our studies.

Although Notch1 target expression was highly upregulated in DP cells of Lck-FADD mice, there seems no obvious effect on the proliferation or survival. The possible explanation may be that the roles of Notch1 in DP cell development was different from that in DN cells, which could be proved by normal positive selection in DP cells where Notch1 signaling was highly activated.

Besides being cytoplasmic as a DR, the FADD protein is also expressed in the nucleus of many types of cells. ${ }^{31}$ It was suggested that its nuclear localization relies on a nuclear localization sequence and a nuclear export signals that reside in the death-effector domain of FADD. ${ }^{31}$ The phosphorylation at serine 191 was also found essential for the nuclear localization of mouse FADD. ${ }^{40}$ In contrast to pro-apoptotic cytoplasmic FADD, nuclear FADD is implicated in other mechanisms. Constitutive phosphorylation of FADD at serine 191 may lead to its mislocalization in the nucleus of T cells after activation and result in early cell cycle defects. ${ }^{41}$ Nuclear localization and high levels of phosphorylated FADD in tumor cells correlates with increased activation of NF- $\kappa B .{ }^{42}$ Therefore, FADD could transcriptionally regulate the activation of signaling pathways. However, no DNA-binding motif has been found in the FADD sequence, and thus, it is probable that FADD may bind other proteins to form a functional transcription factor complex rather than binds directly to promoter or enhancer sequences. The NF- $\mathrm{BB}$ activator NKAP, which was proved to localize in the nucleus, may be a potential medium to associate with FADD and regulate gene transcription. ${ }^{30} \mathrm{We}$ have shown that FADD deficiency leads to decreased NKAP expression and abnormal activation of Notch1 signaling pathway in thymocytes. In vitro experiments, FADD was observed to associate with NKAP and maintain its stabilization in nucleus, therefore, their disassociation may be involved in downregulation of NKAP. The mechanism of FADD-NKAP interaction and its regulation in thymocytes is under investigating.

\footnotetext{
Materials and Methods

Mice. The generation and genotypes of FADD ${ }^{\text {lox/lox }}$ CD4-Cre and FADD lox/lox Lck-Cre mice were assessed as previously described. ${ }^{26,28}$ Briefly, the Tg-FADD/FADD ${ }^{+/-}$mice were bred again to $\mathrm{FADD}^{-1-}$ mice to generate $\mathrm{Tg}$ FADD/FADD ${ }^{-1-}$ mice. The Tg-FADD line that carried the lowest copy number was bred to CD4-Cre/FADD ${ }^{+1-}$ or Ick-Cre/FADD ${ }^{+1-}$ animals to generate Tg-FADD/FADD ${ }^{-1-} /$ CD4-Cre mice (called CD4-FADD) or Tg-FADD/FADD ${ }^{-1-}$ / Ick-Cre mice (called Lck-FADD) and their littermate controls (Tg-FADD/FADD ${ }^{-1-}$ or $\mathrm{Tg}-\mathrm{FADD} / \mathrm{FADD}^{+/-}$). The mice were housed in an Association for
}

Assessment and Accreditation of Laboratory Animal Care Jiangsu Province credited SPF animal facility in Nanjing Drum Tower Hospital and all animal protocols are approved by the Animal Care and Use Committee of the School of Life Sciences of Nanjing University.

Plasmids and recombinant DNA. Plasmids of FADD and its mutant were constructed as described. ${ }^{43}$ Full-length mouse NKAP CDNA were obtained from $\mathrm{NCBI}$ and was generated by PCR amplification, which also introduced restriction sites for subcloning into PRK5HA vector.

Transient transfection and immunoprecipitation assays. 293T cells were transfected with Lipofactmin2000 (Invitrogen, Carlsbad, CA, USA) according to the manufacturer's protocol. Cells were lysed in $500 \mu \mathrm{l}$ lysis buffer consisting of PBS supplemented with $2 \mathrm{mM}$ EDTA, $50 \mathrm{mM} \mathrm{NaF}, 1 \% \mathrm{NP} 40$ detergent, phosphatase and protease inhibitor cocktails (Sigma, St. Louis, MO, USA), $0.2 \%$ SDS and $0.5 \%$ sodium deoxycholate. Lysates were incubated on ice for $20 \mathrm{~min}$, and clarified in a microcentrifuge before adding mouse anti-HA Ab for IP (Millipore, Billerica, MA, USA). The anti-Flag and anti-HA Abs used in western blotting were from Sigma and Millipore.

Protein preparation and immunoblotting. Protein extracts were prepared by whole-cell lysis with $420 \mathrm{mM} \mathrm{NaCl}$ lysis buffer $(20 \mathrm{mM}$ Tris, $\mathrm{pH}$ 7.5, $0.1 \%$ BSA, $1 \mathrm{mM}$ EDTA, $1 \%$ Nonidet P-40) supplemented with protease inhibitors. Protein extracts were separated by gel electrophoresis on a SDS-polyacrylamide gel and transferred to a PVDF membrane overnight at $4{ }^{\circ} \mathrm{C}$. Membranes were blocked for at least $1 \mathrm{~h}$ in PBS-Tween-5\% milk. Abs against Notch1 (Epitomics, Burlingame, CA, USA) were diluted 1/500 in PBS-Tween-5\% milk and incubated with the membrane for $2 \mathrm{~h}$ at room temperature. Abs against cleaved Notch1-val1744 (Cell Signaling Technology, Beverly, MA, USA) were diluted $1 / 500$ in PBS-Tween $5 \%$ BSA and incubated with the membrane overnight at $4{ }^{\circ} \mathrm{C}$. Blots were washed with PBS-Tween $5 \% \mathrm{BSA}$ and incubated with HRP-conjugated $\mathrm{Ab}$ for $1 \mathrm{~h}$ at room temperature. Proteins were visualized by incubation with $\mathrm{ECL}$ reagent and exposure to film.

Annexin V staining. For DN thymocytes, thymocytes were harvested, stained with cell surface markers and stained for annexin $V$ according to the manufacturer's instructions (BD Biosciences, San Jose, CA, USA). For DP thymocytes, total thymocytes were cultured in serum-free medium (Cellgro COMPLETE; Mediatech, Inc., Manassas, VA, USA) at $37^{\circ} \mathrm{C}$ in 24 -well plates $\left(2 \times 10^{6}\right.$ cells per well) for $0,20 \mathrm{~h}$ before staining for cell surface markers and annexin $\mathrm{V}^{44}$

EdU incorporation studies. Mice were injected intraperitoneally with $100 \mu \mathrm{g}$ of EdU in PBS. After $4 \mathrm{~h}$, thymi were harvested and single-cell suspensions were prepared and stained for cell surface markers. Cells were then prepared for EdU detection as per the manufacturer's instructions. ${ }^{45}$

Abs and flow cytometry analysis. All Abs were from eBiosciences (San Diego, CA, USA) unless otherwise stated. For flow cytometric analysis, the following Abs were used: anti-CD4 (GK1.5), anti-CD8 (53-6.7), anti-CD25 (PC61.5), anti-CD44 (IM7), anti-CD27 (LG.7F9), anti-CD69 (H1.2F3), anti-TCR $\beta$ (H57-597), anti-CD5 (53-7.3), anti-CD24 (M1/69) and anti-CD127 (A7R34). Abs were all APC, FITC, PE, PE-cy7 or PE-cy5 conjugates. For staining, cells were plated in tubes at a density of $5 \times 10^{5}$ to $1 \times 10^{6}$ cells per sample. Fluorochromeconjugated Abs were added to cells and incubated on ice for $30 \mathrm{~min}$. Cells were washed three times, and analyzed by flow cytometry on a FACS Calibur (BD Biosciences) flow cytometer using (Flow Jo, Ashland, OR, USA) software. Pre-TCR stimulation and phosphospecifc flow cytometry was performed as previously described. ${ }^{46}$ Isolation of thymic T-cell subsets were performed as previously described. ${ }^{47}$

Measurement of $\Delta \Psi \mathrm{m}$. Isolated thymocytes were surface stained with florochrome-conjugated anti-CD4, anti-CD8, anti-CD44 and anti-CD25 for $30 \mathrm{~min}$ on ice and were washed three times with PBS containing $1 \%$ BSA. Cells were then incubated for $15 \mathrm{~min}$ at $37^{\circ} \mathrm{C}$ with $2 \mu \mathrm{M} \mathrm{JC}$-1 (BD MitoScreen, San Jose, CA, USA) at a density of $1 \times 10^{6}$ cells $/ \mathrm{ml}$ in $0.5 \mathrm{ml}$ working solution. After two washes, cells were resuspended in $0.5 \mathrm{ml}$ working solution and were analyzed immediately by flow cytometry. 
Quantitative RT-PCR. DNA or mRNA was isolated from MEF or sorted thymocytes populations. cDNA generated with Superscript II was amplified and used for quantitative real-time RT-PCR (qRT-PCR) analyses for Notch1, Hes1, CD25 and Deltex1, as well as $\beta$-actin as an internal control. An ABI RT-PCR System (Applied Biosystems, Carlsbad, CA, USA) was used, and error was calculated via the $2-\Delta \Delta C T$ method. $^{48}$

Immunofluorescence microscopy. Unfixed thymi were embedded in OCT compound (Sakura, Chuo-ku, Tokyo, Japan), cut, fixed in acetone and stained as previously described. ${ }^{49}$ The primary Abs used were rabbit anti-FADD (EP887Y), rabbit anti-Notch1 (EP1238Y), rabbit anti-Jagged1 (EPR4290), rabbit anti-Jagged2 (EPR3646) (Epitomics), rabbit anti-NKAP (Sigma), rat anti-CD4 (GK1.5), rat anti-CD8 (YTS169.4), rabbit anti-DL1 (30B11.1(14)), rabbit anti-DL4 (Abcam, Cambridge, MA, USA), rat anti-CD44 (IM7), and biotinylated rat anti-CD25(PC61) (BD Biosciences). Secondary reagents used were Alexa 488-streptavidin, Alexa 488 and Alexa 594-conjugated goat anti-rabbit IgG (Jackson ImmunoResearch, West Grove, PA, USA). Sections were first blocked for $1 \mathrm{~h}$ using $4 \%$ goat serum, then labeled with primary Abs followed by the secondary Abs. Nuclear DNA was stained using 4', 6-diamidino-2-phenylindole (DAPI). Images were then visualized by microscopy (Carl Zeiss Axioplan 2, Göttingen, Germany).

SiRNA and in vitro transfection. The endogenous expression of NKAP of MEF cells was knocked down by transfection with a NKAP-specific siRNAs (5'-GCAGAAGAGAUUAAGUGAAUU-3') using Amaxa Nucleofector (Lonza, Visp, Switzerland) according to the manufacturer's instructions. The effects of the three siRNA were measured using Q-PCR and western blotting. A non-silencing RNA oligo with the sequence $5^{\prime}$-UUCUCCGAACGUGUCACGUTT- $3^{\prime}$ (GenePharma, Shanghai, China) was used as a control.

\section{Conflict of Interest}

The authors declare no conflict of interest.

Acknowledgements. We are grateful to grants from the National Key Basic Research Program from Ministry of Science and Technology (2012CB967004, 2011CB933502), the Chinese National Nature Sciences Foundation (81121062, 30425009, 30330530, 30270291), the Jiangsu Provincial Nature Science Foundation (BK2011228, BZ2011048, BZ2012050), Bureau of Science and Technology of Changzhou (CM20122003, CZ20120004, WF201207) and NIH grant CA920596.

1. Carpenter AC, Bosselut R. Decision checkpoints in the thymus. Nat Immunol 2010; 11: 666-673.

2. Kruisbeek AM, Haks MC, Carleton M, Michie AM, Zuniga-Pflucker JC, Wiest DL. Branching out to gain control: how the pre-TCR is linked to multiple functions. Immunol Today 2000; 21: $637-644$.

3. Kadesch T. Notch signaling: the demise of elegant simplicity. Curr Opin Genet Dev 2004; 14: $506-512$.

4. Maillard I, Fang T, Pear WS. Regulation of lymphoid development, differentiation, and function by the Notch pathway. Annu Rev Immunol 2005; 23: 945-974.

5. Sambandam A, Maillard I, Zediak VP, Xu L, Gerstein RM, Aster JC et al. Notch signaling controls the generation and differentiation of early $T$ lineage progenitors. Nat Immunol 2005; 6: 663-670.

6. Allman D, Sambandam A, Kim S, Miller JP, Pagan A, Well D et al. Thymopoiesis independent of common lymphoid progenitors. Nat Immunol 2003; 4: 168-174.

7. Bell JJ, Bhandoola A. The earliest thymic progenitors for $T$ cells possess myeloid lineage potential. Nature 2008; 452: 764-767.

8. Wolfer A, Wilson A, Nemir M, MacDonald HR, Radtke F. Inactivation of Notch1 impairs VDJbeta rearrangement and allows pre-TCR-independent survival of early alpha beta lineage thymocytes. Immunity 2002; 16: 869-879.

9. Maillard I, Tu L, Sambandam A, Yashiro-Ohtani Y, Millholland J, Keeshan K et al. The requirement for Notch signaling at the beta-selection checkpoint in vivo is absolute and independent of the pre-T cell receptor. J Exp Med 2006; 203: 2239-2245.

10. Schmitt TM, Ciofani M, Petrie HT, Zuniga-Pflucker JC. Maintenance of T cell specification and differentiation requires recurrent notch receptor-ligand interactions. J Exp Med 2004; 200: 469-479.

11. Ciofani M, Knowles GC, Wiest DL, von Boehmer H, Zuniga-Pflucker JC. Stage-specific and differential notch dependency at the alphabeta and gammadelta $T$ lineage bifurcation. Immunity 2006; 25: 105-116.
12. Ciofani M, Zuniga-Pflucker JC. Notch promotes survival of pre-T cells at the beta-selection checkpoint by regulating cellular metabolism. Nat Immunol 2005; 6: 881-888.

13. Michie AM, Chan AC, Ciofani M, Carleton M, Lefebvre JM, He Y et al. Constitutive Notch signalling promotes CD4 CD8 thymocyte differentiation in the absence of the pre-TCR complex, by mimicking pre-TCR signals. Int Immunol 2007; 19: 1421-1430.

14. Newton K, Harris AW, Bath ML, Smith KG, Strasser A. A dominant interfering mutant of FADD/MORT1 enhances deletion of autoreactive thymocytes and inhibits proliferation of mature T lymphocytes. EMBO J 1998; 17: 706-718.

15. Yeh WC, de la Pompa JL, McCurrach ME, Shu HB, Elia AJ, Shahinian A et al. FADD: essential for embryo development and signaling from some, but not all, inducers of apoptosis. Science 1998; 279: 1954-1958.

16. Chinnaiyan AM, O'Rourke $\mathrm{K}$, Tewari M, Dixit VM. FADD a novel death domain-containing protein, interacts with the death domain of Fas and initiates apoptosis. Cell 1995; 81: 505-512.

17. Zhang J, Winoto A. A mouse Fas-associated protein with homology to the human Mort1/FADD protein is essential for Fas-induced apoptosis. Mol Cell Biol 1996; 16 2756-2763.

18. Chinnaiyan AM, O'Rourke K, Yu GL, Lyons RH, Garg M, Duan DR et al. Signal transduction by DR3, a death domain-containing receptor related to TNFR-1 and CD95. Science 1996; 274: 990-992.

19. Hsu H, Shu HB, Pan MG, Goeddel DV. TRADD-TRAF2 and TRADD-FADD interactions define two distinct TNF receptor 1 signal transduction pathways. Cell 1996; 84: 299-308.

20. Kuang AA, Diehl GE, Zhang J, Winoto A. FADD is required for DR4- and DR5-mediated apoptosis: lack of trail-induced apoptosis in FADD-deficient mouse embryonic fibroblasts. J Biol Chem 2000; 275: 25065-25068.

21. Sprick MR, Weigand MA, Rieser E, Rauch CT, Juo P, Blenis J et al. FADD/MORT1 and caspase- 8 are recruited to TRAIL receptors 1 and 2 and are essential for apoptosis mediated by TRAIL receptor 2. Immunity 2000; 12: 599-609.

22. Wilson NS, Dixit V, Ashkenazi A. Death receptor signal transducers: nodes of coordination in immune signaling networks. Nat Immunol 2009; 10: 348-355.

23. Zhang J, Cado D, Chen A, Kabra NH, Winoto A. Fas-mediated apoptosis and activationinduced T-cell proliferation are defective in mice lacking FADD/Mort1. Nature 1998; 392: $296-300$.

24. Newton K, Harris AW, Strasser A. FADD/MORT1 regulates the pre-TCR checkpoint and can function as a tumour suppressor. EMBO J 2000; 19: 931-941.

25. Zhang J, Kabra NH, Cado D, Kang C, Winoto A. FADD-deficient T cells exhibit a disaccord in regulation of the cell cycle machinery. J Biol Chem 2001; 276: 29815-29818.

26. Kabra NH, Kang C, Hsing LC, Zhang J, Winoto A. T cell-specific FADD-deficient mice: FADD is required for early T cell development. Proc Natl Acad Sci USA 2001; 98: 6307-6312.

27. Zhang Y, Rosenberg S, Wang H, Imtiyaz HZ, Hou YJ, Zhang J. Conditional Fas-associated death domain protein (FADD): GFP knockout mice reveal FADD is dispensable in thymic development but essential in peripheral T cell homeostasis. J Immunol 2005; 175: 3033-3044.

28. Osborn SL, Diehl G, Han SJ, Xue L, Kurd N, Hsieh K et al. Fas-associated death domain (FADD) is a negative regulator of T-cell receptor-mediated necroptosis. Proc Natl Acad Sci USA 2010; 107: 13034-13039.

29. Tanigaki K, Tsuji M, Yamamoto N, Han H, Tsukada J, Inoue $\mathrm{H}$ et al. Regulation of alphabeta/gammadelta $\mathrm{T}$ cell lineage commitment and peripheral $\mathrm{T}$ cell responses by Notch/RBP-J signaling. Immunity 2004; 20: 611-622.

30. Pajerowski AG, Nguyen C, Aghajanian H, Shapiro MJ, Shapiro VS. NKAP is a transcriptional repressor of notch signaling and is required for T cell development. Immunity 2009; 30: 696-707.

31. Gomez-Angelats M, Cidlowski JA. Molecular evidence for the nuclear localization of FADD. Cell Death Differ 2003; 10: 791-797.

32. Beisner DR, Chu IH, Arechiga AF, Hedrick SM, Walsh CM. The requirements for Fas-associated death domain signaling in mature $\mathrm{T}$ cell activation and survival. $\mathrm{J}$ Immunol 2003; 171: 247-256.

33. Lee PP, Fitzpatrick DR, Beard C, Jessup HK, Lehar S, Makar KW et al. A critical role for Dnmt1 and DNA methylation in T cell development, function, and survival. Immunity 2001; 15: 763-774.

34. Maltzman JS, Kovoor L, Clements JL, Koretzky GA. Conditional deletion reveals a cell-autonomous requirement of SLP-76 for thymocyte selection. J Exp Med 2005; 202: 893-900.

35. Orban PC, Chui D, Marth JD. Tissue- and site-specific DNA recombination in transgenic mice. Proc Natl Acad Sci USA 1992; 89: 6861-6865.

36. Allen JM, Forbush KA, Perlmutter RM. Functional dissection of the Ick proximal promoter. Mol Cell Biol 1992; 12: 2758-2768.

37. Luo H, Charpentier T, Wang X, Qi S, Han B, Wu T et al. Efnb1 and Efnb2 proteins regulate thymocyte development, peripheral $T$ cell differentiation, and antiviral immune responses and are essential for interleukin-6 (IL-6) signaling. J Biol Chem 2011; 286: 41135-41152.

38. Yashiro-Ohtani $\mathrm{Y}, \mathrm{He} \mathrm{Y}$, Ohtani $\mathrm{T}$, Jones ME, Shestova $\mathrm{O}, \mathrm{Xu} \mathrm{L}$ et al. Pre-TCR signaling inactivates Notch1 transcription by antagonizing E2A. Genes Dev 2009; 23: 1665-1676. 
39. Ishikawa Y, Onoyama I, Nakayama KI, Nakayama K. Notch-dependent cell cycle arrest and apoptosis in mouse embryonic fibroblasts lacking Fbxw7. Oncogene 2008; 27: 6164-6174.

40. Osborn SL, Sohn SJ, Winoto A. Constitutive phosphorylation mutation in Fas-associated death domain (FADD) results in early cell cycle defects. J Biol Chem 2007; 282 22786-22792.

41. Bhojani MS, Chen G, Ross BD, Beer DG, Rehemtulla A. Nuclear localized phosphorylated FADD induces cell proliferation and is associated with aggressive lung cancer. Cell Cycle 2005; 4: 1478-1481.

42. Chen G, Bhojani MS, Heaford AC, Chang DC, Laxman B, Thomas DG et al. Phosphorylated FADD induces NF-kappaB, perturbs cell cycle, and is associated with poor outcome in lung adenocarcinomas. Proc Natl Acad Sci USA 2005; 102: 12507-12512.

43. Cheng W, Wang L, Zhang R, Du P, Yang B, Zhuang H et al. Regulation of protein kinase $\mathrm{C}$ inactivation by Fas-associated protein with death domain. J Biol Chem 2012; 287 26126-26135.

44. Kortum RL, Sommers CL, Alexander CP, Pinski JM, Li W, Grinberg A et al. Targeted Sos 1 deletion reveals its critical role in early T-cell development. Proc Natl Acad Sci USA 2011; 108: $12407-12412$.

45. Salic A, Mitchison TJ. A chemical method for fast and sensitive detection of DNA synthesis in vivo. Proc Natl Acad Sci USA 2008; 105: 2415-2420.

46. Janas ML, Varano G, Gudmundsson K, Noda M, Nagasawa T, Turner M. Thymic development beyond beta-selection requires phosphatidylinositol 3-kinase activation by CXCR4. J Exp Med 2010; 207: 247-261.
47. Perchonock CE, Pajerowski AG, Nguyen C, Shapiro MJ, Shapiro VS. The related adaptors, adaptor in lymphocytes of unknown function $X$ and Rlk/ltk-binding protein, have nonredundant functions in lymphocytes. J Immunol 2007; 179: 1768-1775.

48. Livak KJ, Schmittgen TD. Analysis of relative gene expression data using real-time quantitative PCR and the 2(-delta delta C(T)) method. Methods 2001; 25: 402-408.

49. Fiorini E, Merck E, Wilson A, Ferrero I, Jiang W, Koch U et al. Dynamic regulation of notch 1 and notch 2 surface expression during T cell development and activation revealed by novel monoclonal antibodies. J Immunol 2009; 183: 7212-7222.

cc) $\odot$ Cell Death and Disease is an open-access journal published by Nature Publishing Group. This work is licensed under a Creative Commons Attribution-NonCommercialNoDerivs 3.0 Unported License. The images or other third party material in this article are included in the article's Creative Commons license, unless indicated otherwise in the credit line; if the material is not included under the Creative Commons license, users will need to obtain permission from the license holder to reproduce the material. To view a copy of this license, visit http://creativecommons.org/ licenses/by-nc-nd/3.0/

Supplementary Information accompanies this paper on Cell Death and Disease website (http://www.nature.com/cddis) 